\title{
Free Protoporphyrin Measurement
}

National Cancer Institute

\section{Source}

National Cancer Institute. Free Protoporphyrin Measurement. NCI Thesaurus. Code C147341.

The determination of the amount of free protoporphyrin present in a sample. 